GRASAS Y ACEITES 65 (4)

October-December 2014, e050

ISSN-L: 0017-3495

doi: http://dx.doi.org/10.3989/gya.0229141

\title{
A simple method for purification of deodorizer distillate from Indian rice (Oryza Sativa) bran oil and preparation of phytosterols
}

\author{
R.G. Raja Rajan and A.G. Gopala Krishna ${ }^{\bowtie}$ \\ Department of Lipid Science and Traditional Foods CSIR-Central Food Technological Research Institute Mysore - 570 020, India \\ Corresponding author: aggk_55@yahoo.com; gopalag@cftri.res.in
}

Submitted: 19 February 2014; Accepted: 30 July 2014

\begin{abstract}
SUMMARY: Samples of rice bran oil deodorizer distillates (RBO DOD-1 and RBO DOD-2) were studied for their physicochemical characteristics. The samples were semisolid and had a dark color. The free fatty acid values were $59.2 \%$ and $86.0 \%$, the unsaponifiable matter was $18.7 \%$ and $7.75 \%$ and the phytosterol contents were $8.71 \%$ and $4.22 \%$, respectively for the deodorizer distillates studied. A simple method of silica gel percolation was developed to purify DOD to obtain phytosterol concentrate fractions (PCF) and a brown color and bad odor fraction (BCBOF). The color values were reduced by $72.8 \%$ and $73.0 \%$ of lovibond units in the PCF for DOD-1 and DOD-2 respectively, had no bad odor and were increased in the phytosterol concentration to $12.4 \%$ and $5.9 \%$. The PCF was further processed to prepare high purity phytosterols. An HPLC analysis of the phytosterol mixture showed it to be formed by $\beta$-sitosterol $(38.2 \%)$, stigmasterol $(34.9 \%)$, campesterol $(9.5 \%)$ and other sterols $(17.4 \%)$.
\end{abstract}

KEYWORDS: Brown color and bad odor fraction (BCBOF); Compounds responsible for brown color of RBO DOD; High purity phytosterols; Phytosterol concentrate fraction (PCF)

RESUMEN: Método simple para purificación de destilados de desodorización de aceites de salvado Arroz (Oryza sativa) de India y preparación de fitosteroles. Se estudiaron las características físico-químicas de muestras de destilados de desodorización de aceites de salvado de arroz (RBO DOD-1 y RBO DOD-2). Las muestras eran semi-sólidas y tenían un color oscuro. Los valores de ácidos grasos libres fueron $59,2 \%$ y $86,0 \%$, materia insaponificable $18,7 \%$ y $7,75 \%$ y contenido de fitoesteroles de $8,71 \%$ y $4,22 \%$, respectivamente, para los destilados de desodorización estudiados. Se desarrolló un método simple de filtración mediante sílica gel para purificar DOD y obtener concentrados de fitosteroles (PCF) y una fracción de color marrón y olor desagradable (BCBOF). Los valores de color se redujeron en un 72,8\% y el 73,0\% de unidades Lovibond en el PCF para DOD-1 y DOD-2, respectivamente, no tenían mal olor y aumentaron su concentración en fitoesteroles al $12,4 \%$ y $5,9 \%$. El PCF se procesó adicionalmente para preparar fitosteroles de alta pureza. El análisis por HPLC mostró que la mezcla de fitosteroles estaba formada por $\beta$-sitosterol $(38,2 \%)$, estigmasterol $(34,9 \%)$, campesterol $(9,5 \%)$ y otros esteroles $(17,4 \%)$.

PALABRAS CLAVE: Compuestos responsables del color marrón de RBO y DOD; Concentrado de fitosteroles (PCF); Fitosteroles de alta pureza; Fracción Marrón y maloliente (BCBOF)

Citation/Cómo citar este artículo: Raja Rajan RG, Gopala Krishna AG. 2014. A simple method for purification of deodorizer distillate from Indian rice (Oryza Sativa) bran oil and preparation of phytosterols. Grasas Aceites 65 (4): e050. doi: http://dx.doi.org/10.3989/gya.0229141.

Copyright: (C) 2014 CSIC. This is an open-access article distributed under the terms of the Creative Commons Attribution-Non Commercial (by-nc) Spain 3.0 Licence. 


\section{INTRODUCTION}

Plant sterols also called as phytosterols include over 250 different sterols and related compounds from various plant and marine sources and these are categorized as 4-desmethyl sterols, 4- $\alpha$-monomethyl sterols and 4,4-dimethyl sterols based on their structure and biosynthesis (Akihisa et al., 1991). Phytosterols are the major constituents of the unsaponifiable fraction of the majority of vegetable oils with corn oil reaching the highest content among all vegetable oils (800-1500 mg.100 $\mathrm{g}^{-1}$ ) (Phillips et al., 2005). The major phytosterols in vegetable oils are $\beta$-sitosterol, campesterol, and stigmasterol, which account for $65 \%, 30 \%$ and $3 \%$ of total dietary phytosterol intake (Moreau et al., 2002; Weihrauch and Gardner,1978; Ostlund, 2002). Phytosterols are known to provide health benefits in terms of the lowering of cholesterol levels and the recommended dietary intake of phytosterols for hypocholesterolemic effects are 1500-3000 mg $\cdot$ day $^{-1}$ (Hendriks et al., 1999).

Deodorizer distillate (DOD) is a waste product of the deodorization process, which is a complex mixture of free fatty acids, monoacylglycerol, diacylglycerols, triacylglycerols, sterols, steryl esters, tocopherols, hydrocarbons, broken down products of fatty acids such as aldehydes, ketones, and oxidized products (Ramamurthi and Mccurdy, 1993). Vegetable oils contain $0.1-1 \%$ of phytosterols whereas the DOD from soybean oil contains $4-9 \%$ of phytosterols and hence make it a rich source of phytosterols (Sakina Khatoon et al., 2010). India is the largest producer of rice bran oil in the world, and the potential value of RBO DOD has not yet been assessed.

A few sophisticated and expensive methods are available for the preparation of phytosterols from the DODs of soybean, sunflower and rice bran oil, and they are patented processes (Sakina Khatoon et al., 2010; Moreira and Baltanas, 2004; Sugihara et al., 2010). The purification of DOD to produce a product which is free of bad odor and dark color has not been attempted so far. In the present study the results of a simple method developed to purify DOD followed by the preparation of high purity phytosterols are shown.

\section{MATERIALS AND METHODS}

\subsection{Materials}

Two samples of DODs were obtained from a rice bran oil (RBO) industry which uses the physical refining method (M/s A P Solvex Private Limited, Dhuri, Punjab) and termed as DOD-1 and DOD-2. Standard chemicals, mixed fatty acid methyl esters, phytosterols ( $\beta$-sitosterol, campesterol, stigmasterol) and $\alpha$-tocopherol were purchased from Sigma Chemical Co. (St Louis, USA). Solvents and other chemicals used were of analytical grade.

\subsection{Physicochemical characteristics}

The two DODs were analyzed for characteristics such as free fatty acid value (FFA), peroxide value $(\mathrm{PV})$, color, saponification value $(\mathrm{SV})$, and unsaponifiable matter (USM) according to AOCS official methods (Firestone, 1998). The total tocopherol content of the DOD samples was determined according to the IUPAC Method No. 2.301 (Paquot and Havtfenne, 1987).

\subsection{Determination of phytosterol contents}

The phytosterol contents were determined according to the procedure of Holen (1985). The phytosterol composition was determined using HPLC (model LC-10AVP, Shimadzu corporation, Kyoto, Japan) with a C18 column (ODS column $150 \mathrm{~mm} \times 4.6 \mathrm{~mm}$ id) using a UV detector set at $206 \mathrm{~nm}$. The mobile phase consisted of methanol/ water $(99: 1.0 ; \mathrm{v} / \mathrm{v})$, the samples were dissolved in chloroform and $10 \mu \mathrm{L}$ were injected into the HPLC. The phytosterols were identified and quantified using standard $\beta$-sitosterol, campesterol, and stigmasterol.

\subsection{Determination of acylglycerol composition}

Since the DOD samples had high FFA contents $(59.2 \%$ and $86.0 \%)$, the removal of the FFA was necessary for the estimation of the acylglycerol composition of the DOD samples. Sodium hydroxide (1N) was used to neutralize the FFA and the neutral oil from the soap was extracted using hexane $(50 \mathrm{~mL} \times 3)$ extractions. Ethyl alcohol $(10 \%)$ was used to wash the combined hexane extracts until free of alkali. The neutral oil (NO) was obtained after desolventizing the hexane fraction in a flash evaporator. The acylglycerol compositions of the NO were determined according to the AOAC official method (Firestone, 1998) using silica gel column chromatography. The column was packed with silica gel $(30 \mathrm{~g})$ and the sample $(1 \mathrm{~g})$ was dissolved in chloroform $(15 \mathrm{~mL})$ and transferred into the column. Solvent elutions were made in the following sequence: benzene $(200 \mathrm{~mL}), 10 \%$ diethyl ether in benzene $(20 \mathrm{~mL}$ of diethyl ether $+180 \mathrm{~mL}$ of benzene), and diethyl ether ( $200 \mathrm{~mL}$ ) to elute triacylglycerol, diacylglycerol + FFA and monoacylglycerol fraction, respectively. The solvents were removed in a flash evaporator under vacuum at $40{ }^{\circ} \mathrm{C}$ and the individual fraction of acylglycerol was determined gravimetrically.

\subsection{Purification of DOD}

A simple silica gel percolation method was developed to purify DOD through decolorization and deodorization. A silica gel (100-200 mesh size) was heated at $105{ }^{\circ} \mathrm{C}$ for 6 hours to remove moisture and later hydrated by the addition of water $(5 \%)$. 
The column $(60 \mathrm{~cm}$ length and $4 \mathrm{~cm}$ internal diameter) was packed with silica gel $(100 \mathrm{~g})$ using petroleum ether. DOD (100 g) was mixed with hexane $(500 \mathrm{~mL})(1: 5, \mathrm{w} / \mathrm{v})$ and transferred to the column and allowed to percolate at a flow rate of 2-3 $\mathrm{mL} / \mathrm{min}$ and the fraction was collected and labeled as phytosterol concentrate fraction (PCF) which was devoid of color and bad odor. Later the second solvent system consisting of a mixture of two solvents, (3:1 of ethanol in hexane) was poured onto the column and allowed to pass through the column to obtain the second fraction, termed as brown color and bad odor fraction (BCBOF). The two fractions were desolventized and kept separately until analysis.

\subsection{Preparation of phytosterol mixture}

A high purity phytosterol mixture from the PCF of DOD-1 was prepared according to the procedure of Sakina Khatoon et al. (2010). Briefly, the PCF was refluxed on a boiling water bath containing potassium hydroxide (50\% in water) for $2 \mathrm{hr}$. After refluxing, it was cooled to room temperature, extracted 6 times to get the unsaponifiable matter fraction. Ethyl alcohol (10\%) was used to remove the alkali present in the petroleum ether fraction. Later the solvent was removed in a flash evaporator, and the obtained residue was weighed to get the percentage of unsaponifiable matter. The unsaponifiable matter was diluted with hexane $(1: 10, \mathrm{w} / \mathrm{v})$ and water $(10 \%)$ was added and mixed well using a mechanical stirrer for $10 \mathrm{~min}$, and cooled at $-20^{\circ} \mathrm{C}$ for $72 \mathrm{~h}$ to obtain phytosterol crystals, which were then filtered under vacuum to get a crude product. Then, the crude product was mixed with hexane $(1: 10, \mathrm{w} / \mathrm{v})$ and water $(10 \%)$ once again and cooled at $5{ }^{\circ} \mathrm{C}$ for $2-5 \mathrm{~h}$. Afterwards, the contents were filtered under vacuum to get phytosterol crystals of high purity.

\subsection{Determination of fatty acid composition}

The fatty acid composition of the samples was determined by GC. For this purpose, the sample was converted into fatty acid methyl esters according to the procedure of Van-Wijngaarden (1967). DOD $(200 \mathrm{mg})$ was taken in a test tube and methanolic sodium hydroxide $(2 \mathrm{~mL})(0.5 \mathrm{~N})$ was added and saponified by heating at $50^{\circ} \mathrm{C}$ for $20 \mathrm{~min}$. After saponification, the unsaponifiable matter was extracted by adding hexane $(2 \mathrm{~mL})$ and the hexane extract rejected. The aqueous layer was acidified by adding concentrated $\mathrm{HCl}(0.2 \mathrm{~mL})$ to break up the soap and to facilitate the release of fatty acids. Then hexane $(2 \mathrm{~mL})$ was added to recover the fatty acids. The obtained fatty acids were converted into fatty acid methyl esters by treating with boron trifluoride $(1 \mathrm{~mL})$ in methanol. The identification of fatty acids was carried out using standard fatty acid methyl esters. The prepared fatty acid methyl esters were analyzed using a gas chromatograph (model GC-2010, Shimadzu Corporation, Kyoto, Japan) equipped with a data processor and fitted with an FID detector and RTx-1 fused silica column (30 $\mathrm{m} \times 0.32 \mathrm{~mm}$ id). Injector temperature: $230{ }^{\circ} \mathrm{C}$, detector temperature: $250^{\circ} \mathrm{C}$ and column oven initial temperature: $120^{\circ} \mathrm{C}$ with $5{ }^{\circ} \mathrm{C}$ increase per minute and finally held at $220^{\circ} \mathrm{C}$ for 10 minutes. The total run-time of the program was 30 minutes.

\subsection{Statistical Analysis}

All experiments and analyses were carried out in triplicate, and the obtained results were analyzed for mean and standard deviations. Data were analyzed using the statistical program-GraphPad InStat Demo [DATASET1.ISD]. A two-tailed $p$ value was determined to show the significant differences and a significant difference value was considered only when the $\mathrm{p}$ value $\leq 0.05$.

\section{RESULTS AND DISCUSSION}

\subsection{Physico-chemical characteristics of DOD}

The three main objectives of the current study were to analyze the physico-chemical characteristics of two different DODs, the purification of DODs and the preparation of high purity phytosterols. The two DOD samples (DOD-1 and DOD-2) were examined for their physico-chemical characteristics and are presented in Table 1. Both the DODs were dark brown in color, of soft solid consistency at room temperature. The free fatty acid value, peroxide value and color values of DOD-1 and DOD-2 were $59.2 \%, 86.0 \% ; 2.93$ meq $\mathrm{O}_{2} \cdot \mathrm{kg}^{-1}, 2.87 \mathrm{meq} \mathrm{O}_{2} \cdot \mathrm{kg}^{-1}$, and 55.0, 52.0 Lovibond units, respectively. The neutral oil (NO) contents were $22.1 \%$ and $6.3 \%$ for DOD-1 and DOD-2 with the saponification values of $153.6 \mathrm{mg} \mathrm{KOH} \cdot \mathrm{g}^{-1}$ and $176.7 \mathrm{mg} \mathrm{KOH} \cdot \mathrm{g}^{-1}$ indicating varied glyceride composition and unsaponifiable matter. The acylglycerol composition of the DOD-1 was $18.7 \%, 2.9 \%$ and $0.2 \%$ for triacylglycerol, diacylglycerol and monoacylglycerol, whereas for DOD-2 it was $5.4 \%, 0.7 \%$ and $0.05 \%$, respectively, indicating variations in the compositions of the two DODs studied. Also, the unsaponifiable matter and phytosterol contents were $18.7 \%, 7.7 \%$ and $8.7 \%, 4.2 \%$ for DOD-1 and DOD-2, respectively, indicating variations in their compositions of unsaponifiable matter. The PCF of DOD-1 was chosen for the preparation of high purity phytosterols as it had higher unsaponifiable matter and phytosterol content when compared with DOD2. The total tocopherol contents (which includes all tocopherols and tocotrienols) of DOD-1 and DOD-2 were 1238.7 and $1095.1 \mathrm{mg} \cdot \mathrm{kg}^{-1}$. The PCF fraction of the DODs may also be considered as raw materials for the preparation of a nutraceutical products having the original nutraceuticals present in the starting DODs. 
TABle 1. Physico-Chemical Characteristics of RBO DODs.

\begin{tabular}{lcc}
\hline Parameters & DOD-1 & DOD-2 \\
\hline Physical appearance & Brown color solid at RT & Brown color solid at RT \\
Free Fatty acid value (\%) & $59.2 \pm 0.15^{\mathrm{a}}$ & $86.0 \pm 1.1^{\mathrm{b}}$ \\
Peroxide value (meq $\left.\mathrm{O}_{2} \cdot \mathrm{kg}^{-1}\right)$ & $2.93 \pm 0.25^{\mathrm{a}}$ & $2.87 \pm 0.08^{\mathrm{a}}$ \\
Color $(5 \mathrm{R}+\mathrm{Y})$ & $55.0 \pm 2.0^{\mathrm{a}}$ & $52.0 \pm 2.0^{\mathrm{a}}$ \\
Saponification value $\left(\mathrm{mg} \mathrm{KOH} \cdot \mathrm{g}^{-1}\right)$ & $153.6 \pm 0.72^{\mathrm{a}}$ & $176.7 \pm 1.69^{\mathrm{b}}$ \\
Neutral oil (\%) & $22.1 \pm 1.0^{\mathrm{a}}$ & $6.25 \pm 1.2^{\mathrm{b}}$ \\
Unsaponifiable Matter (\%) & $18.70 \pm 0.15^{\mathrm{a}}$ & $7.75 \pm 0.13^{\mathrm{b}}$ \\
Phytosterol Content $(\%)$ & $8.71 \pm 0.23^{\mathrm{a}}$ & $4.22 \pm 0.37^{\mathrm{b}}$ \\
Total Tocopherols $\left(\mathrm{mg} \cdot \mathrm{kg}^{-1}\right)$ & $1283.7 \pm 9.6^{\mathrm{a}}$ & $1095.1 \pm 18.5^{\mathrm{b}}$ \\
Glyceride composition $(\%)$ & & \\
Triglyceride & $18.7 \pm 0.3^{\mathrm{a}}$ & $5.4 \pm 0.2^{\mathrm{b}}$ \\
Diglyceride & $2.9 \pm 0.2^{\mathrm{a}}$ & $0.7 \pm 0.1^{\mathrm{b}}$ \\
Monoglyceride & $0.2 \pm 0.02^{\mathrm{a}}$ & $0.05 \pm 0.01^{\mathrm{a}}$ \\
\hline
\end{tabular}

Neutral oil $(\%)=[100-($ FFA $\%+$ unsaponifiable matter \%) $]$.

Values given in columns followed by different alphabetical superscripts are significantly different at $\mathrm{P} \leq 0.05$. RT-Room Temperature.

The deacidified PCF from DOD-1 and DOD-2 had enriched unsaponifiable matter $(70.3 \%, 54.2 \%)$, phytosterols $(34.4 \%, 31.1 \%)$ and total tocopherol $\left(4800 \mathrm{mg} \cdot \mathrm{kg}^{-1}, 6900 \mathrm{mg} \cdot \mathrm{kg}^{-1}\right)$ contents making it a product suitable for further purification and utilization as a nutraceutical product for use in foods.

\subsection{Purification of DOD}

The presence of nutraceuticals such as phytosterols, tocopherols and tocotrienols in DOD make it a valuable raw material for their isolation. DOD contains phytosterols in the range of $4.2-8.7 \%$, which makes DOD the obvious starting material for the isolation and preparation of phytosterols (Figure 1) (vegetable oils contain $0.1-1.0 \%$ of phytosterols). The major disadvantage of the DOD is the presence of bad odor, brown color and toxic oxidized substances. DOD was declared as having a brown color and bad odor after comparing it with the physically refined $\mathrm{RBO}$ available commercially in the Indian markets. The results discussed henceforth are presented in Table 2 . The physical appearance of the PCF of DOD-1 and DOD-2 had a light yellow color, and soft solid consistency at room temperature. The free fatty acid contents of the PCF of DOD- 1 and DOD-2 were $64.0 \%$ and $80.8 \%$, whereas the peroxide values of DOD-1 and DOD-2 were $5.83 \mathrm{meq} \mathrm{O}_{2} \cdot \mathrm{kg}^{-1}$ and $14.0 \mathrm{meq} \mathrm{O}_{2} \cdot \mathrm{kg}^{-1}$. The unsaponifiable matter and neutral oil contents of DOD-1 and DOD-2 were $24.6 \%, 7.9 \%$ and $12.0 \%$, $9.8 \%$ in the PCF. The color of the PCF of DOD- 1 and DOD-2 was reduced by $72.8 \%$ (color units reduced to 15 from 55 units) and $73.0 \%$ (color units reduced to 14 from 52 units). The color values of BCBOF of DOD-1 and DOD-2 were increased by approximately

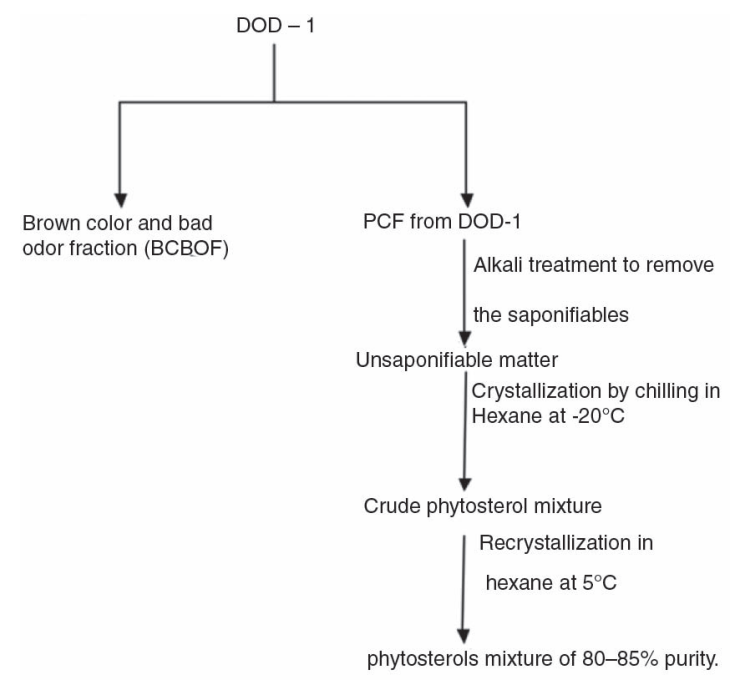

Figure 1. Flow sheet for isolation of phytosterols from PCF through saponification.

$100 \%$ (color units increased to 109 from 55 units) and $111.5 \%$ (color units increased to 110 from 52 units). The phytosterol contents of DOD-1 and DOD-2 were enriched by $42.5 \%$ (Increased to $12.4 \%$ from $8.7 \%$ ) and $40.2 \%$ (Increased to $5.9 \%$ from $4.2 \%$ ) in the PCF. As the PCF was free of any bad odor with $90 \%$ of phytosterols in it and the BCBOF fraction had a bad odor and brown color, the phytosterol content of BCBOF was back-calculated to have $5-10 \%$ of the starting DOD. This is probably the first report on the decolorization and deodorization of DOD from rice bran oil or any other DOD studies reported so far. 
TABLE 2. Physico-chemical characteristics of PCF from DODs

\begin{tabular}{lcc}
\hline Parameters & PCF from DOD-1 & DOD-2 \\
\hline Physical appearance & Light yellow color & Light yellow color \\
Free Fatty acid value $(\%)$ & $64.0 \pm 1.93^{\mathrm{a}}$ & $80.8 \pm 2.2^{\mathrm{b}}$ \\
Peroxide value $\left(\mathrm{meq}_{2} \cdot \mathrm{kg}^{-1}\right)$ & $5.83 \pm 0.4^{\mathrm{a}}$ & $8.9 \pm 0.5^{\mathrm{b}}$ \\
Color $(5 \mathrm{R}+\mathrm{Y})$ & $15.0 \pm 3.0^{\mathrm{a}}$ & $14.0 \pm 3.0^{\mathrm{a}}$ \\
Odor & No bad odor & No bad odor \\
Neutral oil (\%) & $12.0 \pm 2.0^{\mathrm{a}}$ & $9.8 \pm 1.5^{\mathrm{b}}$ \\
Unsaponifiable Matter (\%) & $24.6 \pm 1.0^{\mathrm{a}}$ & $7.9 \pm 0.5^{\mathrm{b}}$ \\
Phytosterol Content $(\%)$ & $12.4 \pm 0.5^{\mathrm{a}}$ & $5.9 \pm 0.37^{\mathrm{b}}$ \\
Total Tocopherols $\left(\mathrm{mg} \cdot \mathrm{kg}^{-1}\right)$ & $1741.7 \pm 13.0^{\mathrm{a}}$ & $1335.3 \pm 22.5^{\mathrm{b}}$ \\
Glyceride composition $(\%)$ & & \\
Triglycerides & $11.4 \pm 0.6^{\mathrm{a}}$ & $9.35 \pm 0.4^{\mathrm{b}}$ \\
Diglycerides & $0.6 \pm 0.05^{\mathrm{a}}$ & $0.33 \pm 0.05^{\mathrm{b}}$ \\
Monoglycerides & $\mathrm{NA}$ & $\mathrm{NA}$ \\
\hline
\end{tabular}

Neutral oil $(\%)=[100-($ FFA $\%+$ unsaponifiable matter \%) $]$.

Values given in columns followed by different alphabetical superscripts are significantly different at $\mathrm{P} \leq 0.05$. RT - Room Temperature, NA-Not Applicable.

\subsection{Fatty acid composition of different fractions of DOD-1}

As the DODs were of high FFA contents, (59.2\% and $87.0 \%$ ) it was interesting to find out whether a single fatty acid predominates or is a mixture of a couple of fatty acids resembling that of the commercially available refined RBO. The fatty acid composition of the DOD-1 and its fractions such as neutral oil (NO) and free fatty acids (FFA) were in the range of lauric acid $0.3-1.4 \%$, myristic acid $0.61-0.87 \%$, palmitic acid 19.6-26.8\%, stearic acid 1.0-1.6\%, oleic acid 35.1-37.8\%, linoleic acid 28.0-34.4\% and linolenic acid $0.9-1.3 \%$. After the purification of DOD, the fatty acid compositions of PCF and BCBOF of both DOD-1 and DOD-2 were examined and indicated similarity with the starting DODs. The fatty acid composition of the PCF and BCBOF of DOD-1 was lauric acid $(0.7-1.2 \%)$, myristic acid $(0.65-0.68 \%)$, palmitic acid $(24.2-28.3 \%)$, stearic acid (1.4-1.5\%), oleic acid (37.9-39.4\%), linoleic acid $(31.2-32.5 \%)$ and linolenic acid $(0.5-0.6 \%)$ which was almost similar to the fatty acid composition of the refined rice bran oil (except linoleic acid content) (Table 3).

\subsection{Fatty acid composition of different fractions of DOD-2}

The fatty acid composition of the DOD-2, NO and free fatty acid fractions were in the range of lauric acid $(0.5-1.4 \%)$, myristic acid $(0.75-0.84 \%)$, palmitic acid $(23.0-27.5 \%)$, stearic acid $(0.6-1.8 \%)$, oleic acid (32.5-36.3\%), linoleic acid (30.8-32.8\%) and linolenic acid $(1.2-1.7 \%)$, respectively (Table 3 ). The fatty acid composition of the PCF and BCBOF of DOD-2 was lauric acid $(0.5-0.6 \%)$, myristic acid $(0.38-0.68 \%)$, palmitic acid (16.3-19.7\%), stearic acid (1.8-1.9\%), oleic acid (36.1-42.0\%), linoleic acid (37.8-39.3\%) and linolenic acid (1.2-1.3\%). Even though the fatty acid composition of DOD-1 was slightly different from rice bran oil, the fatty acid compositions of different fractions of DOD-1 showed insignificant differences. The PCF and BCBOF of DOD-1 did not show any significant difference in the fatty acid composition, and the same thing applies for DOD-2. Gopala Krishna (1993) identified the compounds responsible for the dark color in crude and dewaxed rice bran oil. The fatty acid composition of crude RBO was palmitic acid $(36.5 \%)$, oleic acid $(25.4 \%)$ and linoleic acid $(36.6 \%)$ whereas in the case of dewaxed RBO only palmitic acid $(83.1 \%)$ was present. In the current study, in both DOD-1 and DOD-2, palmitic, oleic and linoleic acids contributed to $95.1-96.1 \%$ of the total fatty acids in BCBOF. The presence of these fatty acids either in oxidized form or as oxidized monoglycerides may be responsible for the brown color of both DOD-1 and DOD-2. This is the first report regarding the compounds responsible for the brown color of the Indian DOD and fatty acid composition of different fractions such as NO, FFA, PCF and BCBOF of both DOD-1 and DOD-2.

\subsection{Phytosterol composition of DOD-1}

The HPLC profile of the phytosterols present in the starting DOD, unsaponifiable matter, crude product and crystallized product were: campesterol: 1.0, 4.73, 8.02 and $9.53 \%$; stigmasterol: $3.68,17.37,29.41$ and $34.94 \%$; and $\beta$-sitosterol: 4.02, 19.0, 32.19 and 
TABLE 3. Fatty acid composition of different fractions of DOD-1 and DOD-2.

\begin{tabular}{lccccccc}
\hline Sample & $\begin{array}{c}\text { Lauric acid } \\
(\mathbf{C 1 2 : 0 )}\end{array}$ & $\begin{array}{c}\text { Myristic acid } \\
(\mathbf{C 1 4 : 0 )}\end{array}$ & $\begin{array}{c}\text { Palmitic acid } \\
(\mathbf{C 1 6 : 0 )}\end{array}$ & $\begin{array}{c}\text { Stearic acid } \\
(\mathbf{C 1 8 : 0 )}\end{array}$ & $\begin{array}{c}\text { Oleic acid } \\
(\mathbf{C 1 8 : 1 )}\end{array}$ & $\begin{array}{c}\text { Linoleic acid } \\
(\mathbf{C 1 8 : 2})\end{array}$ & $\begin{array}{c}\text { Linolenic acid } \\
(\mathbf{C 1 8 : 3 )}\end{array}$ \\
\hline DOD-1 & $1.4 \pm 0.2^{\mathrm{a}}$ & $0.7 \pm 0.05^{\mathrm{a}}$ & $25.1 \pm 0.2^{\mathrm{a}}$ & $1.0 \pm 0.2^{\mathrm{a}}$ & $35.1 \pm 0.2^{\mathrm{a}}$ & $34.4 \pm 0.2^{\mathrm{a}}$ & $1.3 \pm 0.3^{\mathrm{a}}$ \\
NO & $0.3 \pm 0.2^{\mathrm{b}}$ & $0.6 \pm 0.06^{\mathrm{a}}$ & $19.6 \pm 0.7^{\mathrm{b}}$ & $1.4 \pm 0.2^{\mathrm{a}}$ & $37.8 \pm 1.2^{\mathrm{a}}$ & $28.0 \pm 1.6^{\mathrm{b}}$ & $0.9 \pm 0.1^{\mathrm{a}}$ \\
FFA & $0.9 \pm 0.1^{\mathrm{c}}$ & $0.9 \pm 0.2^{\mathrm{b}}$ & $26.8 \pm 0.1^{\mathrm{a}}$ & $1.6 \pm 0.1^{\mathrm{a}}$ & $36.3 \pm 0.3^{\mathrm{a}}$ & $31.2 \pm 0.2^{\mathrm{c}}$ & $1.1 \pm 0.2^{\mathrm{a}}$ \\
PCF & $0.7 \pm 0.2^{\mathrm{c}}$ & $0.7 \pm 0.04^{\mathrm{a}}$ & $28.3 \pm 0.4^{\mathrm{a}}$ & $1.5 \pm 0.1^{\mathrm{a}}$ & $37.3 \pm 0.1^{\mathrm{a}}$ & $31.2 \pm 0.5^{\mathrm{c}}$ & $0.6 \pm 0.1^{\mathrm{b}}$ \\
BCBOF & $1.2 \pm 0.2^{\mathrm{a}}$ & $0.7 \pm 0.03^{\mathrm{a}}$ & $24.2 \pm 0.05^{\mathrm{a}}$ & $1.4 \pm 0.3^{\mathrm{a}}$ & $39.4 \pm 0.3^{\mathrm{b}}$ & $32.5 \pm 0.8^{\mathrm{c}}$ & $0.5 \pm 0.1^{\mathrm{b}}$ \\
DOD-2 & $1.4 \pm 0.2^{\mathrm{a}}$ & $0.8 \pm 0.05^{\mathrm{a}, \mathrm{b}}$ & $23.4 \pm 2.0^{\mathrm{c}}$ & $0.6 \pm 0.1^{\mathrm{b}}$ & $32.5 \pm 0.5^{\mathrm{c}}$ & $32.8 \pm 0.4^{\mathrm{c}}$ & $1.7 \pm 0.1^{\mathrm{c}}$ \\
NO & $0.5 \pm 0.2^{\mathrm{d}}$ & $0.8 \pm 0.2^{\mathrm{a}, \mathrm{b}}$ & $23.0 \pm 0.06^{\mathrm{c}}$ & $1.6 \pm 0.1^{\mathrm{a}}$ & $36.3 \pm 0.9^{\mathrm{a}}$ & $30.8 \pm 1.0^{\mathrm{c}}$ & $1.2 \pm 0.1^{\mathrm{a}}$ \\
FFA & $0.7 \pm 0.2^{\mathrm{c}}$ & $0.8 \pm 0.1^{\mathrm{a}, \mathrm{b}}$ & $27.5 \pm 0.2^{\mathrm{a}}$ & $1.8 \pm 0.1^{\mathrm{a}}$ & $36.2 \pm 0.8^{\mathrm{a}}$ & $31.8 \pm 0.3^{\mathrm{c}}$ & $1.2 \pm 0.1^{\mathrm{a}}$ \\
PCF & $0.5 \pm 0.1^{\mathrm{d}}$ & $0.4 \pm 0.1^{\mathrm{c}}$ & $16.3 \pm 1.2^{\mathrm{d}}$ & $1.8 \pm 0.2^{\mathrm{a}}$ & $42.0 \pm 0.9^{\mathrm{d}}$ & $37.8 \pm 1.0^{\mathrm{d}}$ & $1.3 \pm 0.1^{\mathrm{a}}$ \\
BCBOF & $0.6 \pm 0.1^{\mathrm{d}}$ & $0.7 \pm 0.1^{\mathrm{a}}$ & $19.7 \pm 1.3^{\mathrm{b}}$ & $1.9 \pm 0.1^{\mathrm{a}}$ & $36.1 \pm 0.9^{\mathrm{a}}$ & $39.3 \pm 0.8^{\mathrm{d}}$ & $1.2 \pm 0.1^{\mathrm{a}}$ \\
\hline
\end{tabular}

Values given in columns followed by different alphabetical superscripts are significantly different at $\mathrm{P} \leq 0.05$. NO-Neutral Oil, FFA-Free fatty acids, PCF-Phytosterol concentrate fraction, BCBOF-Brown color and bad odor fraction.

TABLE 4. Phytosterol contents of different fractions of DOD-1 and composition of the crystallized product.

\begin{tabular}{lc}
\hline Fraction & Phytosterol content (\%) \\
\hline DOD-1 & $8.71 \pm 0.2 \mathrm{a}$ \\
Unsaponifiable matter & $41.1 \pm 0.5^{\mathrm{b}}$ \\
Crude extract & $69.6 \pm 5.6^{\mathrm{c}}$ \\
Cystallized product & $82.6 \pm 5.3^{\mathrm{d}}$ \\
Composition of crystallized product & \\
Campesterol & $9.5 \pm 0.07$ \\
Stigmasterol & $34.9 \pm 1.05$ \\
$\beta$-Sitosterol & $38.2 \pm 1.07$ \\
\hline
\end{tabular}

Values given in columns followed by different alphabetical superscripts are significantly different at $\mathrm{P} \leq 0.05$.

$38.23 \%$, respectively (Table 4), which agrees with the results of Van Hoed et al. (2006). The new finding, which is specific to this study, was the purification of DOD to make it free of bad odor and lighter in color, which is enriched in phytosterol contents (40.2$42.5 \%$ ) in both DOD-1 and DOD-2, when compared with the starting DOD. As the DOD was purified, the obtained phytosterol mixture was free of bad odor.

\section{CONCLUSIONS}

Moreira and Baltanás (2004) converted FFA and TG into fatty acid ethyl esters via a transesterification reaction using ethanol for the purification of sunflower oil deodorizer distillate. Sugihara et al. (2010) combined supercritical fluid extraction (SFE), Supercritical fluid chromatography (SFC) and a solvent fractionation method to concentrate squalene and phytosterols from rice bran oil DOD. Although attempts were made in the past to purify phytosterols from both DOD and unsaponifiable matter, in the current study DOD was made free of brown color and bad odor and this was followed by saponification, and the extraction of unsaponifiable matter followed by crystallization. Therefore, the phytosterols produced in the process will have no bad odor. Various studies which involve regularly consumed foods enriched with phytosterol/esters such as cream cheese, salad dressing, yoghurt, milk, cereals bars and margarine are effective in reducing total cholesterol and LDL-cholesterol levels when given to patients with hyperlipidemia. (Goldberg, 2006; Thompson et al., 2002).

The DOD has poor sensory attributes like bad odor, brown color, toxic oxidized substances, and no method was available to purify DOD and to improve its quality. The purification method developed in the current study makes DOD free of bad odor, brown color and toxic oxidized substances. The purified DOD will have a higher value because of the presence of natural antioxidants like phytosterols, tocopherols, tocotrienols and squalene.

\section{ACKNOWLEDGEMENT}

The authors are thankful to Prof. Ram Rajasekharan, Director, CSIR-CFTRI, Mysore for his keen interest and for providing the infrastructural facilities to carry out the work. The authors are thankful to The Indian Council of Medical Research (ICMR) for the award of a Senior Research Fellowship (SRF) to R.G. Raja Rajan.

\section{REFERENCES}

Akihisa T, Kokke W, Tamura T. 1991. Naturally occurring sterols and related compounds from plants in Physiology and Biochemistry of sterols. Ed by Patterson GW and Nes WD. Am. Oil. Chem. Soc. Champaign. IL. pp. 172-228. 
AOAC. 2000. Standard methods for analysis of oils and fats Official Methods of Analysis. Method no. 41.1.61.

Firestone D. 1998. Official methods and recommended practice of the American Oil Chemists Society, AOCS Method no: Ca 5a-40, Cd 8-53, Ce 2-66, Ce 1-63, Ca 6a-40. Am. Oil. Chem. Soc. Champaign. IL. USA.

Goldberg AC. 2006. Effect of plant stanol tablets on low-density lipoprotein cholesterol lowering in patients on statin drugs. Am. J. Cardiol. 97, 376-379. http://dx.doi.org/10.1016/j. amjcard.2005.08.056

Gopala Krishna AG. 1993. Isolation and Identification of the causative factors responsible for the color fixation in rice bran oil. J. Am. Oil. Chem. Soc. 70, 785-788. http://dx.doi. org/10.1007/BF02542601.

Hendriks HF, Westtrate JA, Van Vliet T, Meijer GW. 1999. Spreads enriched with three different levels of vegetable oil sterols and the degree of cholesterol lowering in normocholesterolaemic and mildly hypercholesterolaemic subjects. Eur J. Clin. Nutr. 53, 319-327. http://dx.doi. org/10.1038/sj.ejen.1600728.

Holen B. 1985. Rapid separation of free sterols by reversed phase high performance liquid chromatography. J. Am. Oil. Chem. Soc. 62, 1344-1346. http://dx.doi.org/10.1007/BF02545955.

Moreau RA, Whitaker BD, Hicks KB. 2002. Phytosterols, phytostanols, and their conjugates in foods: structural diversity, quantitative analysis, and health-promoting uses. Prog. Lipid Res. 41 (6), 457-500. http://dx.doi.org/10.1016/ S0163-7827(02)00006-1

Moreira EA, Baltanas MA. 2004. Recovery of phytosterols from sunflower oil deodorizer distillates. J. Am. Oil. Chem. Soc. 81, 161-167. http://dx.doi.org/10.1007/s11746-004-0875-x.

Ostlund Jr RE. 2002. Phytosterols in human nutrition. Annu. Rev. Nutr. 22, 533-549.
Paquot C, Havtfenne A. 1987. Standard methods for analysis of oils, fats and derivatives. International Union of Pure and Applied Chemistry IUPAC, Method no. 2.301.

Phillips KM, Ruggio DM, Ashraf-Khorassani M. 2005. Phytosterol composition of nuts and seeds commonly consumed in the United States. J. Agric. Food. Chem. 53, 9436 9445. http://dx.doi.org/10.1021/jf051505h.

Ramamurthi S, Mccurdy AR. 1993. Enzymatic pretreatment of deodorizer distillate for concentration of sterols and tocopherols. J. Am. Oil. Chem. Soc. 70, 287-295. http:// dx.doi.org/10.1007/BF02545310.

Sakina Khatoon, Raja Rajan RG, Gopala Krishna AG. 2010. Physicochemical characteristics and composition of Indian soybean oil deodorizer distillate and the recovery of phytosterols. J. Am. Oil. Chem. Soc. 87, 321-326. http:// dx.doi.org/10.1007/s11746-009-1499-8.

Sugihara N, Kanda A, Nakano T, Nakamura T, Igusa H, Hara S. 2010. Novel fractionation method for squalene and phytosterols contained in the dodorization distillate of rice bran oil. J. Oleo. Sci. 59, 65-70. http://dx.doi.org/10.5650/jos.59.65.

Thompson G, O'Neill F, Seed M. 2002. Why some patients respond poorly to statins and how this might be remedied. Eur. Heart. J. 23, 200-206. http://dx.doi.org/10.1053/euhj.2001.3071.

Van Hoed V, Depaemelaere G, Vila Ayala J, Santiwattana P, Verhe R, De Greyt W. 2006. Influence of chemical refining on the major and minor components of the rice bran oil. J. Am. Oil. Chem. Soc. 83, 315-321. http://dx.doi.org/ 10.1007/s11746-006-1206-y.

Van-Wijngaarden D. 1967. Modified rapid preparation of fatty acid esters from lipids for gas chromatographic analysis. Anal. Chem. 39, 848-849. http://dx.doi.org/10.1021/ac60251a031.

Weihrauch JL, Gardner JM. 1978. Sterol content of foods of plant origin. J. Am. Diet. Assoc. 73, 39-47. 